\title{
Um estudo sobre aspectos da loucura e do controle social: Análise dos prontuários do Sanatório Pinel de Pirituba (1929- 1934)*
}

\author{
A study about of madness and social control: \\ Analysis of the medical records of the Pinel Sanatorium of Pirituba (1929-1934)
}

\begin{abstract}
Resumo: Os debates em relação à saúde mental tornaram-se destaque no final do século XIX com o surgimento da psiquiatria como especialidade médica e se mantiveram em pauta ao longo do século XX. Um contexto de intensas transformações urbanas, no qual aspectos relacionados à modernização e ao progresso estavam colocados, aprofundando a busca por uma cidade higienizada e pautada pela ordem. Foi pensando em tais questões que esta pesquisa se desenvolveu, tendo como fonte primária os prontuários médicos do Sanatório Pinel de Pirituba, fundado no ano 1929, na cidade de São Paulo. Intencionou-se identificar o perfil dos internos considerados doentes mentais durante os cinco primeiros anos de funcionamento da instituição, de 1929 a 1934, junto às possíveis razões que designaram uma parcela da população ao isolamento.
\end{abstract}

Palavras-chave: Sanatório Pinel de Pirituba, Doença Mental, Controle Social.

\author{
Tuanny Folieni Antunes Lanzellotti \\ Mestranda em História pela \\ Universidade Federal de São Paulo \\ tuannylanzellotti@gmail.com
}

\begin{abstract}
Debates regarding mental health have become prominent in the late nineteenth century with the emergence of psychiatry as a medical specialty and remained on the agenda throughout the twentieth century. A context of intense urban transformations, in which issues related to modernization and progress were placed, deepening the search for a sanitized city ruled by order. It is considering such issues that this research is developed, having as its primary source the medical records of Sanatório Pinel de Pirituba, founded in 1929 , in the city of São Paulo. It intends to identify the profile of internal considered mentally ill, during the first five years of operation of the institution, 1929-1934, and the reasons that have designated this portion of the population to isolation.
\end{abstract}

Keywords: Sanatório Pinel de Pirituba, Mental Illness, Social Control.

* Financiamento da pesquisa: Processo no 2014/26162-0, Fundação de Amparo à Pesquisa do Estado de São Paulo (FAPESP). 


\section{O surgimento de uma instituição: Sanatório Pinel de Pirituba}

O Sanatório Pinel de Pirituba, no momento de sua fundação, detinha um projeto arquitetônico moderno e também de inspiração americana, com infraestrutura adequada e que incluía uma horta, para fins de terapia. Constata-se que o terreno onde foi construído pertencia à Fazenda Anastácio, no bairro de Pirituba, São Paulo, região de grande concentração de áreas verdes e sítios (LIMA-HERNANDES, 2008: 02). Sua criação fora idealizada pelo médico psiquiatra Antonio Carlos Pacheco e Silva, figura influente no período. Dentre as razões de sua fundação, no ano de 1929, alguns motivos foram levantados, entre os quais, a necessidade de se ter novos leitos em hospitais psiquiátricos, já que o Hospital Psiquiátrico do Juquery ${ }^{1}$, público e inaugurado em 1898 na cidade de Franco da Rocha, encontrava-se naquele momento com superlotação (MELONI, 2000: XI).

Outro fator a se considerar, é que o Sanatório Pinel deveria suprir as necessidades de inovações terapêuticas no país, algo que só era possível em clínicas bem equipadas, o que de certa forma nos deixa indícios sobre o público ao qual estaria destinado, tendo em vista que se tratava de uma instituição privada e de serviços pagos. Seu projeto também foi considerado inovador, pois, em seu espaço, as mais modernas teorias e técnicas de tratamento psiquiátrico estiveram em teste e sujeitas a aprovação, voltadas ao reconhecimento de métodos mais eficientes (MELONI, 2000: XV). De acordo com Andrea Tavares Meloni (2000: XIII), o denominado "Movimento de Higiene Mental" também influenciou na criação da instituição e no seu funcionamento.

Segundo Maria Lucia Boarini e Milena Luckesi de Souza, tal "Movimento" foi caracterizado pela questão da eugenia e organizou-se a partir do início do século XX nos Estados Unidos, devido à publicação da autobiografia de Clifford Beers em 1908, $A$ mind that found itself. Nesse texto, Beers relatava sua experiência de internação em vários hospitais e casas de saúde, o que despertou a atenção dos neuropsiquiatras (BOARINI \& SOUZA, 2008: 275). Em maio de 1908, foi fundada a Sociedade de Higiene Mental de Connecticut e, em 1909, o Comitê Nacional de Higiene Mental em Nova Iorque. Tais instituições influenciaram a criação dos chamados serviços abertos, dos ambulatórios psiquiátricos e dos serviços sociais, tendo sido a partir das

$1 \mathrm{O}$ Juquery foi uma importante instituição voltada ao combate da doença mental, onde também se fizeram presentes questões referentes ao controle social e a normatização dos comportamentos. Na obra $O$ Espelho do Mundo: Juquery, a história de um asilo, a historiadora Maria Clementina Pereira Cunha dedicou-se exclusivamente ao estudo de tal instituição. 
experiências dos Estados Unidos que o movimento teria se difundido para outros países (BOARINI \& SOUZA, 2008: 275).

No Brasil, segundo as mesmas autoras, em 1923, o movimento da higiene mental teria sido consolidado por meio da criação da Liga Brasileira de Higiene Mental (LBHM), fundada no Rio de Janeiro, sendo dirigida por psiquiatras e composta por membros da elite e da classe médica brasileira e tornando-se o grande centro de propaganda em favor da higidez mental (BOARINI \& SOUZA, 2008: 275). O Sanatório Pinel, por sua vez, não estaria isento das influências do pensamento eugênico, uma vez que seu fundador afirmava: "A eugenia poderia assegurar uma harmonia social, que visava não apenas a ausência de uma enfermidade, mas um estado completo de bemestar físico, mental e social" (PACHECO \& SILVA, 1952: 07).

Pacheco e Silva colaborou com a direção da Organização Mundial de Saúde Mental e foi o fundador da Liga Paulista da Higiene Mental (LPHM) em 1926, entidade que promovia campanhas com o intuito de educar a população sobre os supostos riscos da mistura racial, do uso de bebidas alcoólicas, do sexo praticado fora do casamento, da entrada de imigrantes "degenerados" no país, da suposta anormalidade das práticas homossexuais, das crenças das religiões espíritas, entre outras (TARELOW, 2011: 04). O mesmo também assumiu a direção do Juquery, em 1923, em um momento no qual as instituições públicas de certa forma se confundiam com a figura de sua administração; como salientou Gustavo Tarelow:

Pacheco se tornou uma figura pública influente tanto do ponto de vista da formação de novos profissionais de saúde quanto dos rumos das instituições que atuou. Com uma posição ideológica sempre conservadora, imprimiu em suas publicações e conferências pontos de vista voltados à manutenção da ordem e da moral oriundas das camadas mais abastadas da sociedade de seu período (2011: 01).

Segundo Rita Cristina C. de Medeiros Couto, a psiquiatria brasileira "foi acentuadamente influenciada pelas ideias higienistas, tendo transformado os limites da normalidade em parâmetros de saúde social, que deveria ser defendido da degeneração" (COUTO, 1994: 53). Tal percepção trouxe, por sua vez, a noção de que o corpo tinha de ser higienizado, não só de maneira orgânica, mas também moralmente, em prol da eugenia, em uma concepção de que no Brasil "sanear, significou eugenizar" (STEPAN 
apud COUTO, 1994: 53).

Desse modo, em meio a uma administração pública que encontrou em tais concepções mecanismos para obtenção de um maior controle social ${ }^{2}$, a população esteve submetida não somente às novas noções de higiene impostas à cidade, mas, também, a higiene vinculada ao seu próprio corpo e comportamento. O historiador Luis Ferla também atentou a essa questão em sua obra Feios, sujos e malvados sob medida: a utopia médica do biodeterminismo, São Paulo (1920-1945), quando afirmou que cada vez mais instituições como escolas, hospitais, prisões e hospícios deveriam cumprir o papel de "normatização do indivíduo" e de suas condutas (FERLA, 2009: 30).

Assim, as teorias da degenerescência ${ }^{3}$ foram um eficaz instrumento de controle social, no qual a cidade apareceu como o ambiente ideal para uma proliferação dos "degenerados", algo que de alguma forma deveria ser contido (CUNHA, 1990: 17). Diferentes tipos de "decadentes" presentes na cidade, tais como alcóolatras, prostitutas ou indigentes, representavam aos olhos da sociedade ameaças distintas, como criminal, política ou sanitária, considerados, portanto, possíveis responsáveis pela epidemia, o crime ou a rebeldia social (FERLA, 2009: 28).

Durante a Primeira República já existiam repartições destinadas ao acompanhamento e saneamento de doenças, no entanto, foi a partir do Governo Vargas em 1930, que se alterou substancialmente a configuração dos aparelhos do Estado, no que se refere aos mecanismos de vigilância e controle (MELONI, 2000: XI). Foi criado, no mesmo período, o Ministério da Saúde e Educação, e também estabelecido o Departamento de Assistência aos Psicopatas. Esse último órgão centralizou todos os serviços pertinentes ao setor, transferindo uma parcela significativa de poder para as mãos dos psiquiatras, tornando-os conhecidos e legitimados pelo Estado. Também passou a gerir a rede privada de psiquiatria, que se desenvolveu a partir dos anos de 1920, na qual o Sanatório Pinel está inserido (MELONI, 2000: XI).

Assim, para a análise dos prontuários do Sanatório Pinel, tais questões não

$2 \mathrm{O}$ conceito de controle social é utilizado neste artigo para se referir aos mecanismos que estabelecem uma ordem social, visando disciplinar e submeter à sociedade a determinados padrões, sendo a regulação do comportamento dos indivíduos dentro de uma conduta desejável. Trata-se, nesse sentido, de "um conjunto de métodos pelos quais a sociedade influencia o comportamento humano, tendo em vista manter determinada ordem" (MANNHEIM, 1971: 178).

3 Bénédict Morel (1809-1873) a partir da observação dos pobres e proletários parisienses formulou a teoria de que a loucura era na verdade um subproduto da degeneração. A partir desse momento, portanto, a medicina alienista do período se apropriou tal ideia, ou seja, de que toda loucura tinha uma origem fundada na degeneração e que inclusive, poderia ser transmitida ao longo das gerações. Morel é assim, considerado como um dos precursores do desenvolvimento da teoria da degenerescência (CUNHA, 1990: 23). 
foram descartadas, uma vez que não se pode negligenciar as informações sobre o período e a discussão travada em relação à medicina. Tais práticas médicas se tornavam, de certo modo, um instrumento de controle e poder, influenciando nas transformações da sociedade e de seus comportamentos, ditando o que seria "bom" e "saudável" e o que deveria ser combatido, mesmo que isso implicasse a marginalização de uma parcela da população.

Os prontuários ${ }^{4}$ do Sanatório, portanto, foram analisados mais do que simplesmente como estatística de internações, mas sim, como fontes capazes de dar protagonismo aos que muitas vezes estiveram à margem da sociedade e da história dita como oficial, com o intuito de que sejam percebidos como sujeitos ativos e atuantes, em sua respectiva época.

\section{Sanatório Pinel e seus sujeitos: Homens, mulheres, brasileiros e imigrantes}

Apesar de o Sanatório Pinel ser conhecido ao longo da história principalmente pelas internações femininas, sendo inúmeros os trabalhos dedicados a essa temática e à condição da mulher exposta ao tratamento psiquiátrico, não se pode esquecer os homens que por lá também passaram. Como a análise das fontes permite afirmar, os homens foram maioria durante os cinco primeiros anos de funcionamento do sanatório, e seus prontuários trazem algumas características interessantes, que colaboram para a percepção do perfil social dos internos.

A etnia é outro ponto relevante de percepção, já que dentre os prontuários catalogados - 919 no total, sendo 561 de homens e 358 de mulheres - apenas seis estão preenchidos com etnia "morena", "parda" ou "negra", uma vez que no restante da documentação todos os internos são ditos como "brancos" ou "amarelos", no caso de imigração japonesa. Em uma sociedade que há pouco tempo tinha decidido pelo fim do regime escravocrata, considerando que negros eram a maioria, ao passo que eram renegados às condições mais precárias e ao intenso preconceito que caracterizava o

\footnotetext{
4 A análise dos prontuários foi realizada por meio de uma catalogação em planilhas que visou identificar o perfil social dos internos e reuniu informações como: nome, idade, profissão, etnia, estado civil, naturalidade, nacionalidade, diagnóstico médico, e data de entrada e saída da instituição. As planilhas também foram separadas por gênero, para que as diferenças na internação entre homens e mulheres pudessem ser percebidas mais facilmente. Ao citar os prontuários, o nome dos internos é representado apenas pelas iniciais, de modo a preservar a identidade do paciente e de seus familiares.
} 
comportamento de vastas camadas da população, uma instituição na qual só se faziam presentes os brancos, nos aponta mais uma vez para a identificação do seu público-alvo, os mais abastados ou pertencentes à elite, ou a setores das classes médias urbanas, que tinham aumentado consideravelmente naquelas décadas (SAES, 1996).

Os prontuários masculinos possuem o dado "profissão" mais vezes identificado e também preenchido com maior variedade de ofícios, quando comparado aos femininos. Entre os internos estão médicos, farmacêuticos, guarda-livros, lavradores, escultores, advogados, promotores públicos, bancários, agrônomos, comerciantes, fotógrafos, padres, entre outros. Dentre a tais homens, encontram-se, em sua maioria, os brasileiros, mas há também a presença de imigrantes, no total 105, identificados com a nacionalidade italiana, argentina, portuguesa, síria, japonesa, polonesa, alemã, entre outras. A localização da residência desses internos, contida no prontuário, é uma possibilidade de estudo relevante para a temática da imigração, pois, nota-se pelas fontes que certas nacionalidades se encontram com frequência em uma mesma região.

Um dos casos interessantes é expresso por meio do prontuário do interno S.U., homem, 55 anos, casado, japonês, de etnia amarela, diagnosticado com paralisia geral, internado durante os meses de outubro e dezembro de 1930, como consta em sua ficha (PRONTUÁRIO 151, 1930). Entre as observações feitas pelo médico do Pinel, apontou-se o fato de que S.U. dizia poucas palavras em português e que, portanto, era acompanhado de um intérprete. Curiosa também é a observação feita quanto às pessoas que podiam visitar o doente, em que se insere: "Só as que trouxerem um cartão do Exmo. Sr. Consul Geral do Japão, Seihachi Kimura ou do Sr. Takeo Saito" (PRONTUÁRIO 151, 1930). Essas duas observações assinalam o fato de que S.U. era de alguma forma influente e incluído nas classes financeiras abastadas do período, uma vez que não era qualquer imigrante que possuía um intérprete acompanhante e que necessitava de uma carta de recomendação para a visita.

Maria Célia Lima-Hernandes salientou em seu estudo o fato de que apesar de muitos homens terem passado pelo Pinel, a internação deles realizava-se de forma "sigilosa", sobre o que ela afirma: "Na verdade, muitos foram os pacientes homens que por lá passaram, mas a maioria pertencia a famílias abastadas e invariavelmente possuía curso superior em carreiras de grande projeção social, no entanto essas internações assumiam um caráter sigiloso" (LIMA-HERNANDES, 2008: 02). Talvez por esse sigilo é que o sanatório de Pirituba ficou com sua fama prioritariamente vinculada ao gênero feminino. 
Os diagnósticos eram diversos, tornando-se recorrentes aqueles relacionados com o "Alcoolismo", a "Toxicomania", a "Intoxicação" e outros termos que se articulavam à dependência química de determinada substância. Em um momento no qual a eugenia social estava posta e se lutava contra a "degeneração" física e moral, a dependência química vai ser considerada como uma situação a ser combatida e até mesmo tratada nos hospitais psiquiátricos, já que o alcoolismo era visto como uma das etapas da loucura (COUTO, 1999). Esse é o caso, por exemplo, de P.S.A., 24 anos, branco, português, solteiro e residente em São Paulo-SP, internado entre os anos de 1930 e 1931, diagnosticado como alcoólatra e portador de problemas devido "à infecção syphilitica" (PRONTUÁRIO 182, 1930), sendo a sífilis outro elemento considerado responsável pela degeneração da sociedade.

O alcoolismo foi um diagnóstico recorrente nos prontuários, principalmente dentre os masculinos. A faixa etária dos pacientes considerados alcoólatras é variada, dos 19 aos 66 anos de idade, abarcando desde os jovens aos mais velhos. Na maioria dos prontuários que relatam essa questão observa-se um tempo de internação curto, provavelmente pelos sintomas "desviantes", relacionados a um distúrbio comportamental, cessarem em razão da abstinência da bebida alcoólica. Casos de reincidência também foram encontrados, o que pode ser observado no prontuário do paciente J.A.C., 26 anos e residente na cidade de Santos-SP, diagnosticado como alcoólatra e internado três vezes durante o período de 1931 a 1939, devido aos mesmos sintomas (PRONTUÁRIO 239, 1931).

Os homens, portanto, não estavam imunes aos padrões de comportamentos ditos como ideais, referente aquilo que deveria ser seu papel na sociedade. Competia ao homem o papel de chefe e provedor da família, não cabendo deslizes e fragilidades como a dependência e a melancolia, por exemplo, diagnóstico comum e recorrente nos prontuários. A melancolia e outros diagnósticos relativos à alteração de humor, como a "psicose maníaco depressiva", foram frequentes e considerados como um distúrbio preocupante, principalmente pelo fato de que a variação de humor era comumente observada e relacionada às mulheres e não aos homens. Em relação a essa questão, Couto afirma que quando o homem demonstrava suas fragilidades e o que seria seu lado "feminino" à sociedade e à sua família, a internação também se fazia presente em

\footnotetext{
5 "Psicose maníaco depressiva" é a antiga denominação da psiquiatria ao que hoje conhecemos como "Transtorno Bipolar", caracterizada por alternância de períodos de depressão e de hiperexcitabilidade ou mania. Mais informações sobre o assunto em: MONTANINI \& BANZATO, 2012.
} 
resposta a aquilo que era então um “distúrbio comportamental” a ser combatido (COUTO, 1994: 60).

O caso de J.C.O., 31 anos, branco, brasileiro, solteiro, diagnosticado com esquizofrenia e internado no sanatório entre os anos de 1930 a 1943, demonstra alguns aspectos que podem se relacionar com essas "fragilidades". Em seu prontuário estão presentes reclamações do próprio interno quanto ao seu comportamento, queixando-se de "impotência sexual" e do abandono que teria sofrido pela mulher que amava, duas questões delicadas principalmente quando relacionadas ao universo masculino e patriarcal (PRONTUÁRIO 178, 1930).

Há ainda o caso de L.R., de 18 anos, branco, italiano, solteiro, escultor, residente na cidade de Campinas (SP), com diagnóstico não identificado e internado entre outubro de 1930 e fevereiro de 1931 (PRONTUÁRIO 153, 1930). Consta em seu prontuário a grande paixão que o interno possuía por sua profissão, ficando em estado de êxtase pela arte. Outra curiosidade é a preocupação de sua família em relação ao sentimento de L.R., já que ele estaria muito apaixonado e com atitudes consideradas preocupantes. A família ofereceu ao médico a seguinte informação, descrita no prontuário como:

Por essa ocasião andava também apaixonado, sendo o seu passeio preferido as caminhadas que dava em redor da casa da namorada; uma ocasião, foi mesmo surpreendido a olhar o céu estrelado em êxtase, em frente à casa dela, a altas horas da noite, ficando admirado de ser tão tarde (PRONTUÁRIO 153, 1930).

No caso de L.R. é perceptível como alguns comportamentos normais da juventude, decorrentes das mudanças hormonais e das descobertas em torno do sentimento, também foram vistos como um distúrbio e como algo impróprio, já que nesse caso o paciente fora posto sob suspeita da anormalidade pela devoção que detinha à arte e ao amor. Em seu prontuário não consta nem ao menos o diagnóstico médico, provavelmente por seu caso não corresponder de fato aos sintomas da doença mental. Contudo, L.R. foi submetido ao tratamento durante quatro meses.

Casos em que a família suspeitava de homossexualidade e internavam seus filhos também se fizeram presentes no Sanatório Pinel, como James Green nos elucidou em sua obra Além do carnaval: a homossexualidade masculina no Brasil do século XX. Ao que parece, apenas a "suspeita" em torno de tal orientação sexual, já era suficiente 
para que a família procurasse a "cura" do comportamento visto como desviante.

O prontuário de A.O. chamou a atenção no primeiro instante de análise apenas pelo diagnóstico descrito, denominado pelos médicos como "Inversão Sexual". Trata-se aqui de um paciente de 20 anos, branco, brasileiro, solteiro e residente em Uberlândia MG, internado entre os meses de janeiro e março de 1931 (PRONTUÁRIO 216, 1931). Entre os escritos médicos, consta a seguinte observação: “É perfeitamente consciente. Invertido sexual tendo contraído lues por coito anal. Está de pleno acordo em se internar para tratamento" (PRONTUÁRIO 216, 1931) ${ }^{6}$.

A. O. revelou aos médicos que a homossexualidade para ele era uma opção a fim de provocar o seu pai, com o qual não tinha afinidade. Em relação a essa questão, registrou-se:

Diz que tornou-se pederasta passivo a quatro anos contra a sua vontade e somente por capricho, para desmoralizar o pai com o qual não combinava. Procurava sempre, que seus atos de passividade fossem observados pelo pai ou ao menos deles ficasse ciente. [...] A nosso ver procura dissimular a perversão, alegando motivo que julga justo e como único meio de vingança ao pai. [...] Diz que precisa tratar-se mas para isso não havia necessidade de internação, estando revoltado com o pai por querer deixa-lo internado por mais de um mês. Se assim o pai proceder, quando voltar ao lar continuará a praticar o coito anal para desmoralizar a família (PRONTUÁRIO 216, 1931).

Este prontuário nos oferece algumas possíveis percepções. Primeiro, em relação à visão colocada sobre a homossexualidade no período, vista em tal contexto como um problema a ser solucionado, havendo até mesmo um diagnóstico para tal. Segundo, a manipulação que o próprio interno fez em relação a sua conduta, justamente por deter a consciência de que seu comportamento desagradava sua família e principalmente seu pai. Dessa maneira, a homossexualidade aqui não estava somente relacionada à orientação sexual propriamente dita, mas, sobretudo, vinculada a uma questão moral da sociedade, no qual o paciente consciente dessa "moralização" e do medo dos familiares em relação a esse "desvio", a utilizava como mecanismo de vingança. E mais do que isso, a vingança, em outra possível interpretação, pode ser considerada até mesmo um

\footnotetext{
${ }^{6}$ Neste caso, "lues” é o mesmo que "sífilis.
} 
"artifício" de defesa do paciente, como se o mesmo estivesse tentando se adequar à "normalidade" quando buscou justificar sua ação "desviante".

A política externa ao mundo do sanatório também se relacionava com os casos de internação, como no caso de S.P.M., de 47 anos, branco, sírio, casado, residente em São Paulo, diagnosticado com "excitação maníaca" e internado durantes os meses de outubro e dezembro de 1930 (PRONTUÁRIO 161, 1930). Em seu prontuário consta-se que a "doença" teria se agravado depois da "recente revolução", já que tal homem era amigo de pessoas ligadas ao governo deposto em 1930 e teria ficado inconformado.

Cabe também observar que o Sanatório Pinel não era um hospital psiquiátrico judiciário, mas houve ocorrências de internação relacionadas a crimes, como é o caso de J.B., 35 anos, branco, solteiro e residente em Araraquara-SP, que teria assassinado sua irmã e sido encaminhado ao sanatório. No entanto, o interno, após alguns dias, fugiu e foi posteriormente preso em Taipas (PRONTUÁRIO 31, 1930). Casos como esse foram exceções, mas não se pode anular sua existência.

Prontuário surpreendente e também considerado exceção, dentre os cinco primeiros anos, é o do paciente M.M.S.O., um menino de sete anos de idade, diagnosticado com epilepsia e mantido em internação entre os meses de julho e outubro de 1931 (PRONTUÁRIO 298, 1931). Por meio desse documento é possível supor que o Pinel não tinha estabelecido, pelo menos em seus anos iniciais, um limite mínimo de idade para que a internação e o tratamento ocorressem, aceitando crianças em suas instalações. Além disso, esse aspecto faz com que problemáticas referentes aos limites entre a infância e o tratamento psiquiátrico sejam postas, sendo uma possibilidade de análise em estudos futuros.

Outro aspecto é a percepção da epilepsia como um transtorno mental a ser tratado em isolamento, diagnóstico recorrente na documentação analisada e aplicado a homens e mulheres. A epilepsia, inclusive, foi considerada por muito tempo como uma doença provocada por causas sobrenaturais, em que pessoas portadoras de tal transtorno neurológico eram mantidas afastadas do restante da sociedade, como nos elucida o trabalho "Transtornos mentais associados à epilepsia" da Revista de Psiquiatria Clínica. Os autores ressaltam, ainda, o fato de que nos Estados Unidos, por exemplo, a exclusão de pessoas com epilepsia de locais públicos e leis eugênicas proibindo o casamento de pessoas com epilepsia se perpetuaram até a década de 1970 (MARCHETTI et al., 2000: 171).

Em meio aos brasileiros e aos imigrantes, ainda estão as mulheres internas no 
Sanatório Pinel, brasileiras e também pertencentes a outras nacionalidades, como portuguesas, italianas, belgas, alemãs, tchecas, japonesas, russas, entre outras, todavia em um menor número quando comparadas aos homens imigrantes, correspondendo a um total de 62.

A catalogação dos prontuários elucida para o fato de que as mulheres do Sanatório Pinel eram em sua maioria brancas, brasileiras ou imigrantes, de idades diferenciadas que iam desde jovens com 16 anos até senhoras com mais de 70, geralmente pertencentes às classes médias e altas. O item "profissão" é pouco preenchido quando comparado aos prontuários masculinos, sendo a profissão de "professora" a mais referenciada entre eles, talvez por tal ofício se destinar prioritariamente às mulheres naquele período.

Se a família era importante em tal contexto, a mulher por meio de seu papel de "mãe" era o eixo fundamental, uma vez que a ela cabia à função de educar e cuidar dos filhos, orientando-os a ter boas condutas. Segundo Couto, o papel feminino e seu reconhecimento político estavam dentro de parâmetros normativos que capacitavam a mulher à formação de outros cidadãos, pois sua obrigação era a de reprodução, não somente biológica como ideológica, junto à unidade básica da nação, a família (COUTO, 1994: 55).

Esse discurso relativo à mulher foi uma ideia disseminada ao longo dos tempos, principalmente pela Igreja Católica, detentora de normas e padrões a serem seguidos, e de grande influência no período. O catolicismo, religião oficial do Brasil, defensor do casamento e do cuidado com os filhos, almejava controlar o espaço familiar por meio de um discurso que privilegiava a figura materna, inclusive com a criação de um estereótipo de "santa mãezinha", piedosa, provedora, dedicada, solidária, assexuada e pura, em menção à figura da Virgem Maria (PRIORE, 1990: 06). Tal concepção parece estar incorporada ao discurso médico do período e a mulher que não atendesse a essas características, acabava sob suspeita de anormalidade, como afirmou Cunha:

Do ponto de vista dos padrões construídos pelo saber psiquiátrico, em suas tentativas de generalização e teorização sobre o "normal" e o "patológico", a quebra do modelo normalizado de comportamento feminino significará sempre alguma forma de recusa ou resistência ao papel "natural" de mãe-eesposa (CUNHA, 1989: 130). 
A mulher ideal, portanto, era aquela que cumpria seus deveres como mãe e esposa, prestando contas ainda em relação a sua sexualidade, essa a ser utilizada apenas para fins de reprodução e não como forma de prazer. Segundo Cunha, antes mesmo de Sigmund Freud, a loucura das mulheres já era remetida à esfera da sexualidade, ressaltando as particularidades do corpo feminino onde se buscava sua etiologia (CUNHA, 1989: 130). Ela ressalta ainda que, nesse sentido, o saber alienista teria retomado a antiga representação do corpo feminino como um estranho ser cíclico, de fluxos circulares de um sangue menstrual impuro e denso de humores perigosos, no qual o alienismo teria projetado a partir dessa imagem do corpo feminino a visão inquietante e turbulenta do seu espírito (CUNHA, 1989: 130). Ressaltando que:

Algumas práticas médicas do período [século XIX] ilustram bem a relação direta e imediata que se estabelecia entre o corpo feminino e a loucura: a injeção de água gelada no ânus, a introdução de gelo na vagina, a extirpação do clitóris ou dos órgãos sexuais internos aparecem nos relatos das técnicas de cura do alienismo europeu do século passado, indicando a importância estratégica do controle da sexualidade feminina (CUNHA, 1989: 130).

Esse é um dos aspectos fundamentais quando lidamos com os prontuários femininos. É recorrente a descrição de distúrbios psicológicos relacionados às práticas sexuais que levaram muitas internas ao sanatório, seja por iniciativa de seus pais, irmãos ou pelo próprio marido. $\mathrm{O}$ questionário familiar preenchido no momento da internação nos deixa pistas sobre a importância do corpo para o diagnóstico de loucura, uma vez que a nota contida ao final indica que "quando se tratar de doente do sexo feminino convém assinalar a regularidade das regras, número e decurso das gestações, enfim, todas as particularidades que possam interessar ao médico" (PRONTUÁRIO 207, 1931). Essas questões eram encaradas pela psiquiatria como um diferencial e que, portanto, deveria ser considerada, visando a identificação das causas de enlouquecimento e variações frequentes do temperamento feminino.

Na publicação "Psiquiatria e feminilidade" de Magali Engel, a autora discorre sobre algumas das estratégias de disciplinarização dos corpos utilizadas no contexto de consolidação da psiquiatria e sobre intervenção da mesma nos comportamentos e na sexualidade feminina (2000). A autora também ressalta o fato de que além dos 
comportamentos morais impostos, as especificidades fisiológicas das mulheres foram fatores influentes quanto ao diagnóstico de uma possível doença mental (ENGEL, 2000: $333)$.

Entre os prontuários a importância das questões sexuais é perceptível, como no caso de A.P.G., 34 anos, branca, brasileira, casada, doméstica e residente na cidade de São Paulo, internada em dezembro de 1929 e com saída no mês de novembro de 1937, sendo encaminhada para o Hospital do Juquery no mesmo ano. O campo referente ao seu diagnóstico encontra-se como "não foi identificado", porém, em seu prontuário é descrito que a paciente pronunciava muitas ideias eróticas, era desorientada e com o humor eminentemente variável, passando do riso ao choro com facilidade, possuindo impulsos agressivos (PRONTUÁRIO 07, 1929). Essa oscilação no humor era preocupante aos olhos da medicina, ainda mais quando acompanhada do teor sexual expresso na fala da paciente.

Tal teor sexual também consta para O.S.B., uma mulher de 40 anos, branca, brasileira, viúva e residente na cidade de São Paulo, com profissão não identificada e diagnóstico indicando "demência precoce" (PRONTUÁRIO 162, 1930). Os médicos a descreveram no prontuário com as seguintes características, "ligeira euforia" "exageração da libido" e "exaltação da esfera sexual", remetendo inclusive a sua tentativa de agarrar os próprios médicos do sanatório. Consta que seu comportamento já teria ocasionado outra internação anteriormente, na Casa de Saúde Dr. Homem de Mello, mais um espaço destinado à cura naquele período. O.S.B. já havia tentado até mesmo o suicídio, mas os médicos ressaltavam que ela escrevia cartas aos seus parentes durante a internação, nas quais soava como uma pessoa "normal” (PRONTUÁRIO 162, 1930).

Desse modo, o discurso relativo ao combate à degenerescência e a afirmação da mulher "higiênica", sem vícios e sadia, estava posto. Como ressalta Cunha, tal fala atingia principalmente as mulheres pertencentes à elite, já que essas imposições bem como a tarefa de se dedicar ao lar, aos filhos e marido, não eram compatíveis com as necessidades cotidianas e concretas da grande maioria das mulheres das classes trabalhadoras, pois, elas estariam "impossibilitadas de permanecer no ninho por longos períodos ou de se dedicar completamente à sua sagrada missão" (CUNHA, 1989: 133). Segundo a historiadora:

[...] este enobrecimento do papel e da natureza femininos, enunciado na fala da medicina e da política, como dos demais saberes concernidos pelo tema, 
além de ser datado, pode revelar um sentido histórico mais preciso: ele se volta em primeiro lugar para o público específico capaz de aceitá-lo, difundilo e levá-lo à prática (CUNHA, 1989: 133).

Diversos produtos no período eram voltados ao público feminino, como, por exemplo, as revistas circulantes na época, que serviam de entretenimento e abordavam diferentes questões do cotidiano: moda, comportamento, os novos produtos ligados ao consumo, referentes à beleza e ao uso doméstico, entre outros. Entre essas revistas está "A Cigarra", circulante ao longo do século XX e de certa forma voltada ao público feminino devido às seções que ela continha, como "Vida Doméstica" e "Colaboração das Leitoras", sendo um dos veículos participantes na divulgação de um modo de pensar e viver em São Paulo. ${ }^{7}$ Outro exemplo é a revista "Fon-Fon!", que circulou entre os anos de 1907 a 1945 e ligava-se prioritariamente a um público mais elitista, trazendo uma tendência snob e urbanizante da sociedade, junto com as tendências do progresso e da modernidade (NOGUEIRA, 2010: 65). Era comum nas revistas a presença de manuais que indicavam "como ser a mulher ideal", "como agradar o marido", "como se comportar", "como ser a mãe ideal" e outras inclinações que demonstram de que maneira o pensamento em relação ao papel da mulher estava semeado em meio à sociedade e veiculado por diferentes instâncias.

Junto a esse universo de novidades e de influências sobre o ideal, uma mulher que não se encaixasse nos padrões sociais da época sofria as consequências em torno do preconceito e do julgamento social, havendo pressão até mesmo por parte da própria família. Necessário pensar que tal pressão provinha ainda das próprias mulheres que se viam "fora do padrão", sendo provável que algumas detinham até mesmo um sentimento de culpa relacionado ao seu comportamento, se forçando a um matrimônio e a um controle sexual, por exemplo, mesmo que isso contrariasse seus desejos e interesses. As mulheres, no entanto, que não desejavam o casamento ou o papel de mãe, se transformavam em alvo de desconfiança a respeito de sua normalidade, gerando dúvidas na própria família, que intencionava lhes controlar a conduta e por diversas vezes insistiam em uma "cura” para a questão.

O caso de E.C. nos remete a esse "desvio de padrão", tornando-se clara a diferenciação de seu comportamento. Logo de início seu prontuário chama atenção pelo

\footnotetext{
${ }^{7}$ Os exemplares da revista estão digitalizados e disponíveis no acervo eletrônico do Arquivo Público do Estado de São Paulo (APESP) em: <http://www.arquivoestado.sp.gov.br/memoria/pginterna.php?revista=CIGA>Acesso em: 25 jan. 2016.
} 
tempo de internação a que ela foi submetida ao tratamento, de 1930 até 1944, pois, nos anos iniciais aqui pesquisados foi comum a descrição de um tempo curto de internação, no qual o paciente recebeu alta rapidamente ou foi retirado pela família, mesmo sem alta médica. Além do tempo de internação, outros fatores chamam atenção em sua ficha inicial (PRONTUÁRIO 45, 1930).

O item "profissão" está preenchido, diferentemente da maioria dos outros prontuários femininos que não possuem essa informação, pois, o trabalho exercido fora de casa não era incentivado, principalmente em relação às mulheres pertencentes às classes mais abastadas e elitizadas, ainda que em contrapartida, fosse comum a presença de mulheres mais pobres e das classes trabalhadoras realizando diferentes tipos de ofícios, a fim de se sustentarem.

Trata-se aqui, portanto, de uma professora, solteira e com 50 anos, cujos aspectos do prontuário e da história revelam uma disparidade em relação à maioria. Se coube à mulher cumprir o papel de mãe e esposa, dedicada, submissa e responsável pela manutenção da ordem familiar, uma mulher independente, com profissão e sustento, sem marido e filhos, poderia ser vista como uma ameaça para o bom desenvolvimento da nação, tendo sua postura traduzida como doença mental, o que a levou à internação durante a década de 1930.

Sua independência pode ser traduzida no trecho descrito pelos médicos, onde segue: “Já neste tempo, tornava-se totalmente independente; não admitia intervenção ou conselhos dos paes ou irmãos mais velhos; confiava exclusivamente em si” (PRONTUÁRIO 45, 1930). Ela é caracterizada com "hyperexcitação intelectual” e em seu prontuário existem diferentes referências sobre sua inteligência e seu ofício, sendo uma mulher que "trabalhava demais". Em seu prontuário ainda se inscreve que nos últimos tempos, devido a "abalos moraes por casamentos rompidos", E.C. se tornou agressiva com os próprios pais e irmãos e quase que repentinamente caiu em excitação maníaca (PRONTUÁRIO 45, 1930).

Seu comportamento, por variados fatores, é diferenciado daquilo considerado como "normal" e "ideal", primeiro por ser uma mulher bem-sucedida financeiramente e que tinha o trabalho e a carreira em destaque, como é percebido pela descrição do prontuário. Segundo, por não admitir intervenções em sua vida por parte dos familiares, o que poderia ser considerado pela medicina como um desequilíbrio emocional, e por deter, ao mesmo tempo, grande confiança em si própria. Terceiro, por ser uma mulher independente e que já com 50 anos não teve filhos e era solteira. Por esses fatores é 
possível perceber que E.C. não era o modelo esperado por sua família, sendo incomum na sociedade em geral.

Ao que parece, os médicos encontravam naquilo que não era "normal" para os padrões da época um meio de justificar a internação da paciente. A historiadora Juliana Suckow Vacaro discorre em sua dissertação sobre essa questão e afirma:

Quando se parte de um modelo moral de mulher para diagnosticar o paciente, é possível entender que todo esforço para legitimar cientificamente tal conclusão se faz apenas em relação a este modelo, isto é, as mulheres fora da norma apresentavam a priori uma série de comportamentos interpretados como sintomas doentios de sua doença (VACARO, 2011: 30).

A questão da ausência da maternidade, visto como um problema, também pode ser percebido no caso de V.M.R., 30 anos, branca e brasileira (PRONTUÁRIO 103, 1930). Seu acompanhante ao responder às perguntas médicas quanto aos sintomas e as razões de um possível enlouquecimento, afirmou que tal comportamento poderia estar relacionado ao fato de suas "regras irregulares" e por ela não ter tido filhos, não ser mãe. Afirmação que nos indica mais uma vez a relevância desses tópicos para a sociedade do período.

O caso de A.N.P. expressa algo diferente, mas, que pode ser traduzido em forma de controle no que se refere à degeneração a ser combatida e evitada. A.N.P., mulher, branca, brasileira, solteira, residente na cidade de São Paulo, com entrada no sanatório em 13 de janeiro de 1930 e saída em 25 de janeiro do mesmo ano, segundo os médicos sem alta, mas, com atenuada melhora, teve seu diagnóstico dado como "Intoxicação" (PRONTUÁRIO 26, 1930). Ela já havia sido enviada pelos familiares à Itália para “desintoxicação de morphina" e foi internada no Sanatório Pinel novamente por motivos de dependência química.

Da mesma maneira que existiam casos de internação masculina pela dependência química de diferentes substâncias, o mesmo poderia ocorrer entre as internas. Se o vício e o alcoolismo eram vistos como degradantes para os homens, priorizados na sociedade, é de se supor que o mesmo ocorria com as mulheres, que deveriam atender ao padrão de "santa mãezinha". Foi perceptível a variedade de diagnósticos referentes à dependência química, descrita pelos termos "Intoxicação", "Psicose Auto-Tóxica”, "Toxicomania”, "Auto-Intoxicação", entre outros, em que 
mulheres foram levadas à internação de modo a se livrarem do vício considerado uma das mazelas da sociedade e que, portanto, devia ser controlado e extinto.

A família nesse processo é fundamental, pois a internação pode ser percebida como a maneira pela qual os familiares tratavam suas mulheres desviantes e a facilidade com que estas eram enviadas às instituições psiquiátricas, frequentemente como uma forma disfarçada de puni-las ou de escondê-las aos olhos da vizinhança (CUNHA, 1989: 133). Seja pelos pais ou pelo marido, - uma vez que em muitos dos prontuários eles foram os responsáveis pela internação justamente por não compreenderem o comportamento de suas esposas, as variações de seu humor e até mesmo por motivos de traição - a internação pode ser entendida como uma forma de represália e de exclusão do convívio social.

Essas mulheres, portanto, representavam o fracasso do modelo idealizado de família, que atentavam contra a saúde moralizada (CUNHA, 1989: 133). As questões sociais também estavam postas naquele momento, já que seguir tal padrão e reforçar as características do que seria uma família "de bem", contribuiria para estabelecer parâmetros de superioridade e, simultaneamente, reforçar os elementos de suspeição contra as classes populares (CUNHA, 1989: 133).

Eram, portanto, diversos os aspectos que se relacionavam para que uma mulher aparentemente "normal" fosse internada no Sanatório Pinel em busca de uma cura para seus distúrbios e transtornos. Vale a ressalva de que em muitos dos prontuários os médicos não chegaram a nenhum acordo de diagnóstico, havendo casos como o de M.L.B.P., mulher, 19 anos, branca, brasileira, solteira, residente em São Paulo, com profissão e diagnóstico não identificado (PRONTUÁRIO 158, 1930). Ainda que ela tenha sido encaminhada ao sanatório pelos pais, consta em seu prontuário que a jovem não acusou nenhum tipo de distúrbio mental e mesmo assim ficara internada de outubro de 1930 a fevereiro de 1931.

Essa questão demonstra de certa maneira como a medicina psiquiátrica do Pinel ainda se moldava no período e aceitava em suas dependências diferentes tipos de diagnósticos, até mesmo aqueles que os próprios médicos não avaliavam como doença mental, transparecendo o fato de que o Sanatório também almejava, ao longo dos primeiros anos, um direcionamento. A partir do trabalho com as fontes, foi perceptível como o campo "diagnóstico" por diversas vezes fora preenchido como "não identificado", tanto nos prontuários de mulheres como de homens, em que o paciente permanecia internado pelo desejo de seus familiares ou até a obtenção da dispensa 
médica.

Mais uma vez se destaca o lugar da família, pois mesmo que a medicina não considerasse o paciente como doente, se a internação ainda assim fosse desejada, prevalecia o desejo dos familiares. Entre os diagnósticos atribuídos às mulheres são frequentes os que se relacionam com a variação do humor, sendo um aspecto frequentemente relatado ao longo dos prontuários. Doenças mentais relacionadas à fase da menopausa também se fizeram presentes, no qual os médicos diagnosticavam e relacionavam tais "transtornos" a este período da vivência feminina. Diagnosticadas com "Psicose da Menopausa", os médicos atribuíam às transformações hormonais a variação do comportamento das pacientes, como o caso de M.L.M.M., de 57 anos, branca, brasileira, solteira e residente em São Paulo, que ficou internada durante os meses de janeiro e março de 1931 (PRONTUÁRIO 207, 1931).

Em seu prontuário, a paciente queixava-se de maus tratos, que dizia sofrer por parte dos seus familiares, e ainda afirmava ser vítima de perseguições. Não é possível afirmar que M.L.M.M. sofria de tal distúrbio psicológico, muito menos que era em razão das transformações ocasionadas pela menopausa. No entanto, pode-se afirmar novamente o fato de que para a medicina psiquiátrica do período, a doença mental das mulheres se misturava com as questões referentes ao funcionamento do corpo feminino e seus hormônios. Como afirma Couto: "Tanto a primeira menstruação como a menopausa eram considerados momentos extremamente delicados para a sanidade mental da mulher, bem como período de 'regras', da mesma forma que era comum a 'psicose puerperal' que ocorria durante a gravidez ou no período posterior ao parto" (COUTO, 1994: 57). O diagnóstico "psicose puerperal" também esteve presente ao longo dos prontuários aqui estudados.

Questões relacionadas às "perseguições” é outro aspecto que pode ser observado ao longo da documentação, tanto nos femininos como masculinos. Normalmente tais "alucinações" foram associadas a diferentes diagnósticos, no qual se torna difícil a percepção referente aos limites da doença mental ou de um controle social imposto. $\mathrm{O}$ caso de A.M.Q. nos elucida de certa forma sobre esse aspecto: uma mulher de 59 anos, branca, brasileira e viúva, e que dizia estar envolta por "espíritos de perseguição", mas que não teve seu diagnóstico identificado pelos médicos (PRONTUÁRIO 197, 1931).

Os aspectos relacionados ao espiritismo, em tal contexto, eram problemáticos e também visto como algo a ser combatido. A Igreja Católica, principal força religiosa no período, pregava contra esse tipo de afirmação, bem como a tais crendices em espíritos 
e questões sobrenaturais. Em meio a tal contexto, o espiritismo foi visto como um fator que contribuía para o "enlouquecimento" (COUTO, 1994: 59).

\section{Considerações Finais}

As discussões travadas até aqui, tiveram como intenção abordar outras possibilidades de compreensão sobre aqueles considerados "loucos" na sociedade do fim dos anos de 1920 e início da década de 30, submetidos ao tratamento psiquiátrico não somente por aspectos de "enlouquecimento", mas por outros fatores, esses sim, envoltos pelas normas sociais do período.

Foi possível caracterizar o perfil dos pacientes expostos à internação durantes os cinco primeiros anos da instituição aqui analisada, e como ficou evidente por meio da averiguação das fontes, foram internados durante esses anos homens, mulheres, brasileiros ou imigrantes, provenientes de diferentes lugares. Algo importante que fora percebido é a quase ausência nos prontuários da "etnia negra", já que quase todos os pacientes eram considerados brancos ou amarelos (no caso da imigração japonesa). Por tal indício, e pelo fato de o Pinel ser um sanatório privado e inovador para o período onde os internos deveriam pagar pela permanência e tratamento -, é possível supor que seu funcionamento esteve voltado prioritariamente para as classes médias e altas.

Em meio a essa população internada, revelou-se claramente entre os prontuários como a loucura sob a forma de diagnóstico sujeitou muitos ao isolamento, mesmo que a razão de seu distúrbio não revelasse uma doença mental propriamente dita. É de se conjecturar que muitos sofreram até mesmo um agravamento de suas condições por conta da internação, tornando-se agressivos ou depressivos, devido à contrariedade de se estar em uma instituição como essa, o que os levava, muitas vezes, a negar o tratamento.

Essa negação proveio por parte dos pacientes submetidos ao Sanatório devido à pressão do núcleo familiar que, como foi constatado, desempenhou um importante papel, até mesmo pela importância conferida à família no decurso do período estudado. A difícil convivência no âmbito familiar com o "outro", considerado diferente por não seguir os padrões determinados como "ideais" no período esteve sempre presente. Assim, muitas famílias viam como solução aos "desvios" do seu parente o envio a tais instituições, com o intuito de que se pudesse solucionar aquilo que era considerado problemático, mesmo que hoje aos nossos olhos sejam questões referentes 
principalmente aos comportamentos, e não à saúde mental.

$\mathrm{O}$ aprofundamento do estudo da figura masculina dentro de instituições como o Pinel é outra possibilidade de análise, pois, apesar de os homens serem mais vezes relatados na história dita "oficial", muitos dos papéis em destaque são apenas aqueles referentes à administração, à política e às figuras públicas. Homens que foram renegados à internação psiquiátrica podem nos revelar, a partir de uma abordagem mais detalhada, o outro lado do universo masculino, também exposto às fragilidades e imposições do período, do mesmo modo como ocorreu com as mulheres.

A discussão sobre as mulheres, ao mesmo tempo, nos informa como o controle social do período estava imposto a elas devido aos comportamentos ditos como ideais e correspondentes ao dever da mulher, traduzidos no papel de "mãe", "esposa" e figura fundamental no bom funcionamento do âmbito familiar, chegando a ganhar o papel de "santa mãezinha", essencial na sociedade e defensora das boas condutas.

Tal controle demonstrou-se até mesmo mais rigoroso a elas, principalmente no que se referem às questões sexuais, no qual o corpo feminino era analisado de outra forma devido a suas "particularidades". O incômodo em relação à mulher independente e que não desejava assumir os papéis designados, também estiveram presentes. Essa temática possui, por sua vez, diferentes possibilidades de abordagem, não sendo objetivo deste artigo abarcar todas elas. No entanto, é inegável a relevância do tema para o estudo daquelas que foram, e ainda são, excluídas da história oficial.

Os prontuários como fonte histórica são um relevante material para a pesquisa, pois com sua extensa quantidade de informações possibilitaram importantes reflexões e questionamentos a respeito da sociedade do período, permitindo um estudo para além dos aspectos referentes à medicina psiquiátrica, e apontando novos caminhos para uma análise histórico-social.

Além do enfoque dado, as fontes ainda poderiam servir como objeto de estudo para diferentes áreas. Seria relevante ater-se às questões alusivas aos modos de tratamento e diagnósticos aplicados por uma psiquiatria que ainda tomava suas formas, às questões vinculadas à eugenia social ou a um estudo focado somente nos imigrantes ou em homens, mulheres e crianças separadamente. Enfim, nota-se que são diversas as possibilidades de investigação em relação a tal documentação, ainda mais ao envolver um tema tão delicado e re[significado] ao longo do tempo, como a loucura. 


\section{Fontes}

PRONTUÁRIO 07 (1929) (Ordem 9576). Catálogo Sanatório Pinel I (Arquivo Público do Estado de São Paulo - APESP).

26 (1930) (Ordem 9576). Catálogo Sanatório Pinel I (Arquivo Público do Estado de São Paulo - APESP).

31 (1930) (Ordem 9577). Catálogo Sanatório Pinel I (Arquivo Público do Estado de São Paulo - APESP).

45 (1930) (Ordem 9577). Catálogo Sanatório Pinel I (Arquivo Público do Estado de São Paulo - APESP).

103 (1930) (Ordem 9578). Catálogo Sanatório Pinel I (Arquivo Público do Estado de São Paulo - APESP).

151(1930) (Ordem 9580). Catálogo Sanatório Pinel I (Arquivo Público do Estado de São Paulo - APESP).

153 (1930) (Ordem 9580). Catálogo Sanatório Pinel I (Arquivo Público do Estado de São Paulo - APESP).

158 (1930) (Ordem 9580). Catálogo Sanatório Pinel I (Arquivo Público do Estado de São Paulo - APESP).

161(1930) (Ordem 9580). Catálogo Sanatório Pinel I (Arquivo Público do Estado de São Paulo - APESP).

162 (1930) (Ordem 9580). Catálogo Sanatório Pinel I (Arquivo Público do Estado de São Paulo - APESP).

178 (1930) (Ordem 9580). Catálogo Sanatório Pinel I (Arquivo Público do Estado de São Paulo - APESP).

182 (1930) (Ordem 9580). Catálogo Sanatório Pinel I (Arquivo Público do Estado de São Paulo - APESP).

197 (1931) (Ordem 9581). Catálogo Sanatório Pinel I (Arquivo Público do Estado de São Paulo - APESP).

207 (1931) (Ordem 9581). Catálogo Sanatório Pinel I (Arquivo Público do Estado de São Paulo - APESP).

216 (1931) (Ordem 9581). Catálogo Sanatório Pinel I (Arquivo Público do Estado de São Paulo - APESP).

239 (1931) (Ordem 9582). Catálogo Sanatório Pinel I (Arquivo Público do Estado de São Paulo - APESP).

298 (Ordem 9584). Catálogo Sanatório Pinel I (Arquivo Público do Estado de São Paulo - APESP).

\section{Referências Bibliográficas}

BOARINI, Maria Lucia \& SOUZA, Milena Luckesi de (2008). A deficiência mental na concepção da liga brasileira de higiene mental. Revista Brasileira de Educação Especial. Marília, vol. 14 n. 2, pp. 273-292, maio/ago. Disponível em: $<$ http://www.scielo.br/scielo.php?pid=S1413- 
65382008000200009\&script $=$ sci_arttext $>$. Acesso em: 12 jan. 2016.

COUTO, Rita Cristina C. de Medeiros (1994). Eugenia, loucura e condição feminina. Cadernos de Pesquisa. N. 90, pp. 52-61, ago. Disponível em: $<\mathrm{http}: / /$ www.fcc.org.br/pesquisa/publicacoes/cp/arquivos/882.pdf $>$ Acesso em: 20 jan. 2016.

COUTO, Rita Cristina C. de Medeiros (1999). Nos corredores do Pinel: eugenia e psiquiatria. Tese (Doutorado em História). Universidade de São Paulo, São Paulo.

CUNHA, Maria Clementina Pereira (1986). O espelho do mundo: Juquery, a história de um asilo. Rio de Janeiro: Paz e Terra.

(1990). Cidadelas da ordem: a doença mental da República. São Paulo, 1990.

(1989). Loucura, Gênero Feminino: As Mulheres do Juquery na São Paulo do Início do Século XX. Revista Brasileira de História. São Paulo, vol. 9, n. 18, pp. 121-144, ago./set.

ENGEL, Magali (2000). Psiquiatria e feminilidade. In: PRIORE, Mary Del (org). História das mulheres no Brasil. 3 ed. São Paulo: Contexto. pp.322-362.

FERLA, Luis (2009). Feios, sujos e malvados sob medida: a utopia médica do biodeterminismo, São Paulo (1920-1945). São Paulo: Alameda.

GREEN, James (2000). Além do carnaval: a homossexualidade masculina no Brasil do século XX. São Paulo: Ed. Unesp.

LIMA-HERNANDES, Maria Célia (2008). Prontuários médicos e o corpus do português de São Paulo: vestígios da história social feminina na primeira metade do século XX. Texto originalmente apresentado no XV Congreso Internacional da ALFAL em Montevidéu, agosto. Disponível em: $<$ http://dlcv.fflch.usp.br/sites/dlcv.fflch.usp.br/files/MCAlfal2008.pdf>. Acesso em: 25 jan. 2016.

MANNHEIM, K. (1971). Sociologia sistemática: uma introdução ao estudo da sociologia. 2 ed. São Paulo: Pioneira, 1971.

MARCHETTI, Renato Luiz et al. (2005). Transtornos mentais associados à epilepsia. Revista de Psiquiatria Clínica. São Paulo, vol. 32, n. 3, pp.170-182, maio/jun. Disponível em: <http://www.scielo.br/pdf/rpc/v32n3/a09v32n3.pdf>. Acesso em: 09 jan. 2016.

MELONI, Andrea Tavares (2000). O arquivo do Sanatório Pinel. Informações extraídas do Arquivo Público do Estado de São Paulo. Catálogo Sanatório Pinel - Volume I e II. São Paulo.

MONTANINI, Daniel \& BANZATO, Cláudio E. M. (2012). Do estigma da psicose maníaco-depressiva ao incentivo ao tratamento do transtorno bipolar: a evolução da abordagem em dois veículos midiáticos nos últimos 40 anos. Jornal Brasileiro de Psiquiatria. Rio de Janeiro, vol. 61, n. 2, pp.84-88. Disponível em: $<\mathrm{http} / / / \mathrm{www}$. scielo.br/pdf/jbpsiq/v61n2/05.pdf $>$. Acesso em: 23 jan. 2016.

NOGUEIRA, Clara Asperti (2010). Revista Careta (1908-1922): símbolo da modernização da imprensa no século XX. Revista Miscelânea. Assis, vol.8, pp.6080, jul./dez. Revista de Pós-Graduação em Letras, UNESP - Campus Assis. Disponível em: $<$ http://www.assis.unesp.br/Home/PosGraduacao/Letras/RevistaMiscelanea/v8/cla ra.pdf $>$. Acesso em: 10 jan. 2016.

PACHECO E SILVA, Antonio Carlos (1952). A higiene mental: conceito, generalidade e tendências modernas. São Paulo.

PRIORE, Mary Del (1990). Ao sul do corpo: condição feminina, maternidades e mentalidades no Brasil Colônia. São Paulo.

SAES, Décio Azevedo Marques de (1996). Classe média e política no Brasil - 1930 - 
1964. In: FAUSTO, Boris (org.). História geral da civilização brasileira - Tomo III: O Brasil republicano, vol. 10. Rio de Janeiro: Bertrand Brasil. pp.447-499.

TARELOW, Gustavo Querodia (2011). A moral, a política e algumas questões científicas presentes no Hospital do Juquery: Abordagens de Pacheco e Silva (1923-1950). Revista Histórica do Arquivo Público do Estado de São Paulo (APESP). n. 51, pp.23-34, dez. Disponível em: $<$ http://www.historica.arquivoestado.sp.gov.br/materias/anteriores/edicao51/mater ia03/texto03.pdf> Acesso em: 25 jan. 2016.

VACARO, Juliana Suckow (2011). A Construção do Moderno e da Loucura: Mulheres no Sanatório Pinel de Pirituba (1929 - 1944). Dissertação (Mestrado em História). Universidade de São Paulo, São Paulo.

Artigo recebido em 5 de fevereiro de 2016.

Aprovado em 15 de março de 2016.

DOI: 10.12957/intellectus.2016.23837 